\title{
"The socioeconomic impacts of newly emerged pandemic Covid-19 on the community" in case of Sekela Woreda
}

\author{
Abie Assres Fenta \\ Lecturer in Department of Sociology, At Debre Markos University, Ethiopia \\ DOI: 10.29322/IJSRP.11.03.2021.p11147 \\ http://dx.doi.org/10.29322/IJSRP.11.03.2021.p11147
}

\begin{abstract}
The main purpose of this study has to assess the socioeconomic impacts of newly emerged pandemic covid-19 on the community. To acquire sufficient and detail information regarding the issue, mixed research approach had been utilized, as well as researcher employed a descriptive research design that intends to describe and reckon the socioeconomic impacts of covid-19 on the community. In this research, 319 respondents had been selected from the entire target population by employing both probability and non-probability sampling techniques. Along with probability sampling technique, cluster and simple random sampling methods had been utilized for opted respondents. From the non-probability sampling technique on the other hand, purposive sampling has been employed to attain a pivotal and constructive data that pertinent to the study. The data which have been obtained from the quantitative research methods such as; survey questionnaires will be analyzed through descriptive statistics, frequency of mean, percentage and pie chart, while the qualitative data which had obtained from key informant interview had been analyzed by thematic and content analyses. The finding obtained from the study; among the entire respondents, 288 $(90.3 \%)$ of were not wear mask and keep their physical distance to protect the pervasiveness of the pandemic. Besides, majority of peoples were not goes to hospital to attain primary assistant after the emergency of covid-19. In succinctly, covid-19 brought huge socioeconomic impacts on the community, such as conflict, theft, over crowdedness, burglar, illegal trade, market instability and inflation has been occur hither to. As a result researcher concludes that the perception of community toward the severity of covid-19 is low and inculcated misunderstanding on it. And covid-19 affects the socioeconomic scene of the people unfortunately. As a result, peoples should aware the pandemic severity and take care to be safe, and government stakeholders should make stabilize market inflation.
\end{abstract}

Index Terms- Covid-19, community, perception, socioeconomic impact

\section{INTRODUCTION}

$\mathrm{A}$ reported by World Health Organization (2020), Corona virus disease (COVID-19) is an infectious and an awesome pandemic disease caused by a newly discovered corona virus. The COVID-19 virus spreads primarily through droplets of saliva or discharge from the nose when an infected person coughs or sneezes, so it's important that you also practice respiratory etiquette.

This publication is licensed under Creative Commons Attribution CC BY.

http://dx.doi.org/10.29322/IJSRP.11.03.2021.p11147
COVID-19 is a newly emerged pandemic creating enormous disruption to lives and livelihoods as well as social and economic systems worldwide. The virus is highly contagious and has spread with geometric progression and to every corner of the world. Young people are far more likely to be infected (as carriers) but older persons are more likely to die (Sozi, 2020).

In lower earning countries populations, the economic levels are advents to contract and narrowed by the cause of newly emerging pandemic disease (covid-19) in the nations. As a result, the degree unemployment and the rates of poverty rise and widespread in alarmingly across countries. Around 11 million people had been fall into poverty across East Asia and the Pacific (World Bank, 2020).

Most of Sub-Saharan Africa countries, including Ethiopia, are unlikely to escape the direct and indirect effects of the pandemic and attendant global crisis. While the trajectory of COVID-19 is still at its initial stages in the region, the repercussions of developments elsewhere are already being felt strongly. By 4 May 2020, Ethiopia had 135 confirmed cases and had conducted 18,754 lab tests representing around $0.019 \%$ [9] of the total population (Sozi, 2020).

Notwithstanding, many research investigation had been conducted in associated with the newly emerged pandemic covid19 in Ethiopia, its severity is come to grow hither to. Hereby, the researcher attempted to glance the assumption of community toward the severity of newly emerged pandemic diseases on them and the cares they have experienced in order to escaped from covid-19. Besides, the perceptions of community toward this outrageous disease are varied from society to society. As a result, after examining community attitudes; the researcher had endeavors to deliver and offer awareness for the people toward the erroneous and inequitable perception on the devastating impacts of covid-19 in fact.

\subsection{Objective of the study}

In this investigation; there are general objective, and specific objectives to achieve the ultimate objective of the study

\subsubsection{General objective of the study}

The general objective of this investigation is to assess the socioeconomic impacts of newly emerged pandemic covid-19 on the community

\subsubsection{Specific objectives of the study}

In order to pursue the ultimate objective of the study, the researcher attempted to address these specific objectives which are presented below:- 
$>$ To examine the perception of community toward the newly emerged pandemic Covid-19

$>$ To assess the social impacts of pandemic covid-19 on the community

$>$ To find out the economic impacts of newly emerged covid-19 on the society

\subsection{Scope and justifications of the study}

From the very inception of this study in terms of thematic scene, the researcher has delimiting to assess socioeconomic impacts of newly emerged pandemic covid-19 on the community in 'Sekela Woreda'. Geographically, the research has been conducted in Sekela Woreda, where found in Amhara national region one of among in west Gojjam Woreda. The main reasons that incline me to carry out the research in this spatial are that it aims to understand and reckon the real existences of the problems on the community which has emanated from the newly emerged pandemic disease. Moreover, in methodological wise, the researcher has intended to employ both quantitative and qualitative (triangulation) research approaches which are aimed to ascertain the quality of obtained data. And eventually, in terms of time duration the research has been waited from the onset of November, 2020 up to the middle terms of January, 2021.

\subsection{Significance of the Study}

The main objective of the study is aimed to assess socioeconomic impacts of newly emerged pandemic covid-19 on the community in 'Sekela Woreda'. The finding of the study therefore, deemed to discern and assess the socioeconomic impacts of newly emerged pandemic covid-19 on the community and the perception of community toward severity of covid-19 thoroughly. Inconsequent, after deep reckoning of its implication on the community, government stakeholders may be nongovernmental organizations (NGOs) and ministry of health experts will be expected to take remedies or measurement in order to redress or ameliorate the problems. Furthermore, the study finding will provoke other interested investigators toward the immediate impacts of covid-19 on the community and attempts to provide solutions to redress its socioeconomic vices in Ethiopia in general, and in 'Sekela Woreda' in particular.

\section{REVIEW OF RELATED LITERATURE}

\section{1 social impacts of civid-19}

Greater Horn of Africa is currently experiencing the worst desert locust upsurge in the last 25 or so years. After emerging of Covid-19 pandemic will likely limit control and surveillance operations on impacting supply of pesticides), as well as the deployment of experts to the field. This could cause considerable damage to livelihoods and food supply (WHO, 2019).

As all schools are closed, all school aged children who were enrolled in schools have been affected in terms of daily learning. The most vulnerable and poor children will not benefit from homeschooling during school closures, hence widening inequities in the learning gap between the lowest and highest quintiles (WHO, 2019).

\subsection{Economic impacts of covid-19}

As revealed by Martin, A \& et al (2020), Covid-19 would lead to a massive economic shock to the system. In simulations of a 3-month lockdown, the poverty rate increases from $17.1 \%$ to $25.9 \%$ during the crisis in the Bay Area. Household saving and consumption drop significantly, and the average recovery time for individuals is almost reached to one year.

There are a widespread loss of income and deeper levels of poverty as social distancing intensifies. As a result, the presences of social distancing apply in Ethiopia brought a tremendous impacts on the economy of the country, like on the service industry, tourism and for the sizeable self-employed population and the forth sorts. The combination of labor constraints and limited access to markets will drive poverty and exacerbate food insecurity. Loss of income, especially for those engaged in informal operations where women are over-represented is likely (World Bank, 2020).

\section{RESEARCH METHODOLOGY}

\subsection{Introduction}

In this chapter, background of the study area, target population of the study, prominent research methods that have been employed, tools and other issues are presented. Since, those would have serve as the major instruments that guide to the pace of the research during investigation. Along with this, the researcher also endeavors to put plausible justifications for employing the stated methods. Therefore, there are three main methodological approaches which are adopted in many researches. They are the quantitative, qualitative and mixed research approaches. The choice of any research method is however based on the objective of the study (Kitchin and Tate, 2000). Kitchin and Tate (2000) argues that choosing a research method is not just a case of picking the one that seems the "easiest" but picking the most appropriate relative to the knowledge you require in the research investigation. Amongst those, triangulating both qualitative and quantitative approach (Mixed-method approach) is the most appropriate to reach at a level of truth that enables the researcher to come up with complementary and convergence of facts (Ridenour \& Newman, 2008). Thus, in this study for the purpose of achieving and pursuing the stated research objectives both quantitative and qualitative research approaches had been used to investigate the socioeconomic impacts of newly emerged pandemic covid-19 on the community in 'Sekela Woreda'.

\subsection{Study design}

Descriptive survey describes and interprets what is concerned with conditions and relationships that exist; practices that prevail; beliefs, points of view or attitudes that are held; processes that are going on, effects that are being felt, or trends that are developing. Besides, identify present conditions and point to the present needs, study the immediate status of a phenomenon, find facts, examine the relationship of traits and characteristics (trends and patterns). Since in descriptive research, the data collected is qualitative and quantitative, it gives a holistic understanding of a research topic. The information is varied, diverse, and thorough (Kumar H., 2016). Therefore, this research study is concerned with examining the socioeconomic impacts of newly emerged pandemic disease covid-19 on the community. Hereby, the researcher deemed that the descriptive type of research with cross-sectional research design is the most appropriate design to pursue the setting objectives in due. 


\subsection{Research approach}

There are three main methodological approaches which are adopted in many researches. They are the quantitative, qualitative and mixed research approaches. The choice of any research method is however based on the objective of the study (Kitchin and Tate, 2000). Inconsequent, the ultimate objective of this study is to examine the socioeconomic impacts of newly emerged pandemic disease covid-19 on the community in 'Sekela Woreda'. Accordingly, the use of scientific methods for data collection and analysis make generalization possible with this type of approach. Besides, interaction made with one group can be generalized as per the data obtained from the selected sample. Similarly, the interpretation of research findings need not be seen as a mere coincidence. In a sense that, The study of problem-solving instruction within one particular area or zone can be reflective of the wider society in terms of samples, contents and patterns (Cohen, 2011). Based on the aforementioned justification therefore, the researcher has been obligated to utilize both quantitative and qualitative research approaches during the study. Along with a quantitative research approach, the researcher has employed a survey research method that aims to collect large amounts of data which are pertinent with the stated objectives via questionnaire tool.

On the other hand, qualitative methods employed in data collection give full description of the research with respect to the participants involved. The participants' observation and focused group nature of qualitative research approach create a wider understanding of behavior and the real situations of the issues. Hence, qualitative research approach provides abundant data about real life of people and situations (Leedy, 2014). Therefore, the researcher has employed a qualitative research approach to understand thoroughly the socioeconomic impacts of covid-19 on the community. Along with a qualitative research approach interview had been employed.

\subsection{Data collection methods}

In this research both quantitative and qualitative methods of data collection had been employed. Mixed methods approach as design, combining both qualitative and quantitative research data, techniques and methods within a single research framework. Mixed method approaches may mean a number of different types of methods in a study or at different points within a study or using a mixture of qualitative and quantitative methods. Mixed methods encompass multifaceted approaches that combine to capitalize on strengths and reduce weaknesses that stem from using a single research design. Using this approach to gather and evaluate data may assist to increase the validity and reliability of the research (Muhammad, 2016). As a result, in this research investigation the following research methods had been employed:

\subsubsection{Survey}

It is considered a rapid and relatively cheap method of getting peoples' perceptions, attitudes, personal experiences and opinions about a product, people and situations (Harrison, 2013). In survey, participants respond to questions through interviews or questionnaires and the researcher describes the responses through tables, charts, graphs and so forth. It focuses on variables rather than on individual cases. Survey is one of the main forms of descriptive research that is applied to demonstrate the existing phenomenon without manipulating the data, unlike experimental research that follows a systematic and logical method for answering the question and manipulation is a deliberate part of the experimental research design (Kothari, 2004). Due to this reason, the researcher utilized a survey method of data collection, so as to attain large and good enough information by preparing both open and close-ended questions which are pertinent to the specific objectives of the inquiry and provide to the sample respondents.

\subsubsection{Key Informant Interview}

Interview is the method by which the researcher collects information directly from the respondent. Interview is a very flexible method of data gathering. It uses to gather large amounts of data within a time. It can be used in any type of data gathering questionnaires. Interview is a technique for obtaining, through questions and answers, verbal information from individuals and human groups in order to verify hypotheses or to scientifically describe the social sciences phenomena. It involves the formulation of an instruction, building and planning a thematic guide to listening and intervention strategies. The interview consists of collecting data by asking questions (Abawi K., 2013). According to the above justifications thereof, the researcher utilize interview research method, namely key informant guideline so as to obtain deep and constructive information about the socioeconomic impacts of newly emerged pandemic disease covid-19 on the community.

\subsection{Data collecting instruments}

In the meantime of this research investigation in order to bring appropriate and pertinent data, the research employed both questionnaires and interview guide line.

\subsubsection{Questionnaires}

A questionnaire is a data collection instrument consistent with a series of questions and other prompts for the purpose of gathering information from respondents. Questionnaires allow collection of both subjective and objective data in a large sample of the study population in order to obtain results that are statistically significant and tool for the protection of the privacy of the participants, expressing opinion, and attitude toward social phenomena (Abawi, 2014). Therefore, as per the above justification, the study had employed a questionnaire because it is the major device to gather primary data by using a series of questions that seek to attain efficacious information in pertaining to the specific objectives of the inquiry. In doing so, 319 respondents had been taken for filling the prepared questionnaires.

\subsubsection{Key informant interview guide}

Key informant interviews involve interviewing a select group of individuals who are likely to provide needed information, ideas, and insights on a particular subject. Key informant interview is appropriate for information, ideas about socioeconomic conditions of the area or the general characteristics of the target populations, and when understanding of the underlying motivations and attitudes of a target population (Kumar K., 1989). Hereof, the researcher utilizes key informant guidelines to pose questions to those who have detailed information about the socioeconomic impacts of covid-19 on the community in Sekela Woreda. Amongst them were Woreda health 
experts, Woreda education officer, police officer, small and micro enterprise expert.

\subsection{Sources of data}

This study has been conducted by using both primary and secondary sources of data. Primary data was obtained from the respondent and informants and secondary data was from books and else materials that hold information pertinent to the objective of the inquiry.

\subsubsection{Primary sources of data}

Primary data was obtained by collecting information directly from the respondents by concerning the topic through in questionnaire and interview. The main reason why the researcher intended to employ primary data is to get first hand information from the respondents.

\subsubsection{Secondary sources of data}

Secondary data had been collect from various sources of published materials, including from article journal and from else. The main reason for use secondary data is to support the primary data, through careful review of related documentation.

\subsection{Sampling techniques}

To select sample respondents from the total study population, both probability and non-probability sampling methods will be employed. According to Zikmund (2002), probability sampling means that every item in the population has an equal chance of being included in the sample. One way to undertake random sampling would be if researchers was to construct a sampling frame first and then used a random number generation computer program to pick a sample from the sampling frame (Taherdoost, 2016). In this study therefore, a probability sampling method has been selected, because it avoids biasness and helps to generalize data gained from sample respondents avoiding an error which could arise from sampling. As a result, simple Radom sampling method has been employed.

However, non-probability sampling is generally used in trial research and does not represent the target population. Nonprobability sampling uses subjective judgment and utilizes convenient selection of units from the population. Non-probability sampling methods produce cost savings for personal interview surveys; the resulting samples often look rather similar to probability sample data. In purposive sampling, the participants are selected by the researcher subjectively. The selection is based on the judgment of the researcher. Respondents are not selected randomly but by using the judgment of the interviewers (Ayhan, 2011). Hence, among those non-probabilities sampling techniques, in this investigation purposive sampling has been employed, because the researcher intended to attain good and pertinent data about the socioeconomic impacts of covid-19 on the community and its assumption on the newly emerged pandemic disease. Therefore, $11 \mathrm{key}$ informants were taken to pursue the investigation.

\subsubsection{Sample size determination}

According to Omair (2014), a sample must be of the required size in order to have the required degree of accuracy in the results, as well as to be able to identify any significant difference/association that may be present in the study population determining the minimum required sample size for achieving the main objectives of the study is of prime importance for all studies but is generally neglected by most novice researchers. A common practice is to select all the cases that are available (consecutive sampling) in a given period of time or to select a sample size based on a previous study (Israel GD, 2009). In doing so, sampling selection has been determined through Yemen's sampling selection formula (1967);

Where;

$$
\mathrm{n}=\mathrm{N} / 1+\mathrm{N}\left(e^{2}\right)
$$

$\mathrm{N}=$ total target population of the study

$\mathrm{n}=$ sample size

$\mathrm{e}=$ the margin error

$\mathrm{n}=1572 / 1+1572(0.5)^{2}$

$\mathrm{n}=319$

Therefore, based upon the aforementioned formula, the researcher has takes 319 respondents from the given total target populations.

\subsection{Methods of Data Analysis and Interpretation}

Data analysis is making sense of massive amounts of collected data, reducing the volume of information, identifying significant patterns and constructing a framework for communicating the essence of what the data reveal and, hence, producing findings (Creswell, 2009). In this study therefore, convergent mixed method of data analysis has been employed, while from inception quantitative data has been analyzed and cross check with qualitative data which is obtain from interviewee. As a result, the data that are collect from sample respondents through questionnaire was analyzed through statistical process and some descriptive parameters like percentage, frequency, pie chart and tables. On the other hand, qualitative data such as data from interview and other secondary sources was analyzed in the form to thematic essay. Eventually, the researcher has offer an interpretations and conclusion as per the obtained data from respondents

\subsection{Ethical consideration}

The researcher would take into consideration to protect the privacy, anonymity and confidentiality of the respondents by voluntary consent and informing participants about the overall purpose of the research. Interview, and questionnaire, would not be intentionally pressure to reveal private or personal details and also the researcher takes care not to reveal the identity of individuals implicated in research without their permission and treat research participants fairly and show them respect.

\section{DATA PRESENTATION, ANALYSIS AND INTERPRETATION}

\subsection{Introduction}

This chapter mainly concerned with the analysis, presentation and interpretation of the data which gathered from the respondents and informants, since to acquire the necessary information through questionnaire and key informant interview. This chapter gives detail explanation on the socioeconomic impacts of newly emerged pandemic covid-19 on the community. Therefore, in this section of research investigation, the researcher has endeavored to analyze and interpreted the data based on the responses which had obtained through questionnaire and interviews. The data which had been gathered through questionnaires was analyzed in the form of descriptive statistics such as percentage and frequency and the qualitative data also analyzed through thematically together in similar questions. And eventually, after the data was analyzed in this form the researcher provide an interpretation and conclusion, as well as recommended 
which will served as alternative to ameliorate the severity of the problem by concerned body if it possible.

\subsection{Demographic characteristics of the respondents}

Since, background of information was necessary to know everything from its root, so the researcher has attempted to present the demographic characteristic of the respondents as follows:Sex distribution of both 'respondents and key informants'

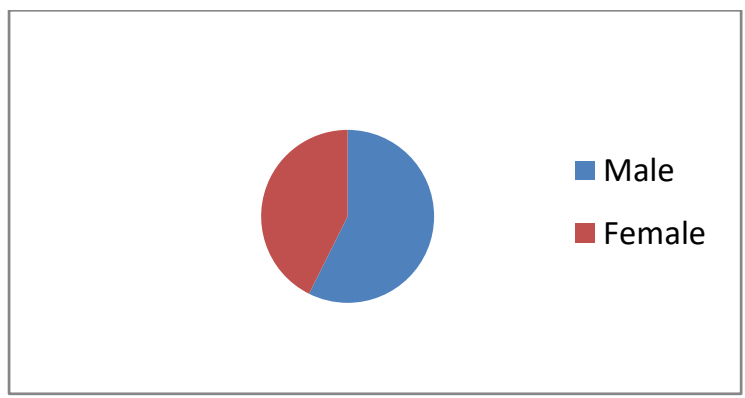

Source: own survey, 2020

As shown in the above pie chart among the total respondents almost all proportion or $183(57 \%)$ of respondents were male, and the least $136(43 \%)$ of respondents in this study were female. Noted that, in this case the researcher, attempted to demonstrate eleven (11) key informants were taken to obtain a pivotal data that pertinent to the objectives of the study. Amongst them were health professionals, Woreda education experts, small and micro enterprise experts and job opportunity creation experts were involved in this investigation.

\subsection{Perception of community toward the newly emerged pandemic Covid-19}

As apparently stated in the objective section of the research; examining the perception of the community toward the newly emerged pandemic disease has been the initial objectives of the inquiry. Hereby, the performance of peoples on the outlined covid19 preventive proclamation and the perception of the community toward the covid-19 in general, had been presented below:-

Table-1 the trend of keeping physical distance

\begin{tabular}{|l|l|l|}
\hline $\begin{array}{l}\text { Have you always keep your } \\
\text { physical distance? }\end{array}$ & Frequency & Percentage \\
\hline Yes & 31 & 9.7 \\
\hline No & 288 & 90.3 \\
\hline Total & 319 & 100 \\
\hline \multicolumn{2}{|l}{ Source: own survey; 2020 }
\end{tabular}

As shown from the above table, the majority of respondent, $288(90.3 \%)$ of them were responded that they were not keep their physical distance unfortunately. On the contrary, the least number of respondent, 31(9.7\%) of this study were keep their physical distance in order to emancipate from covid-19 pandemic. Correspondingly, all key informants inform that all most all residents of this Woreda were not able to keep their physical distance and contact to each other during market transaction and in different social institution centers. They notify that, despite government stakeholders proclaim to keep physical distance and debar and interdicting peoples to exchange greeting with hand no one applied the motto of the country that intended to keep peoples from the victim of newly emerged disease in general and proclamations of the Woreda in particular.

According to the data which has obtained from both respondents and informants therefore, the researcher conclude that Sekela Woreda peoples were not give due attention for the severity of newly emerged pandemic covid-19. Since, peoples of area were not applied covid-19 motto of the world that will help to prevent and protect the pervasiveness of this newly outrageous disease in fact. Overall, the perception of peoples toward the severity and killer of covid-19 is low and small at a large.

\section{Table-2 the trends of wearing mask of the respondents}

\begin{tabular}{|l|l|l|}
\hline $\begin{array}{l}\text { Have you wear mask during } \\
\text { market transaction, and during } \\
\text { festivity ceremony? }\end{array}$ & Frequency & Percentage \\
& & \\
\hline Yes & 31 & \\
\hline No & 288 & 9.7 \\
\hline Total & 319 & 90.3 \\
\hline
\end{tabular}

Source: own survey, 2020

As presented from the above table, almost all respondents which accounts $288(90.3 \%)$ of them were not wear mask which protecting the spread of covid-19 pandemic. However, the small number of respondents, $31(9.7 \%)$ of were accept the principle of country that impels peoples to wear mask during market transact and elsewhere peoples are come to collected and congregate so. Similarly, all key informants offer response toward the habits of mask wearing of peoples is that peoples who come from both rural and urban were failed to wear face mask during market transaction and while they goes to church and elsewhere. As per the responses which had been emanated from respondents and key informants of the study therefore, the researcher conclude that peoples of the Woreda were interact to each other without utilizing mask that covers their noise and moth which expected to protect them from the pandemic covid-19. As, a result, the perception of society toward the severity of covid-19 on the health of peoples is still low and not reckon it in due unfortunately.

\section{Table-3 the perception of respondents toward the severity of} covid-19

\begin{tabular}{|l|l|l|}
\hline $\begin{array}{l}\text { Is newly emerged covid-19 is } \\
\text { killer? }\end{array}$ & Frequency & Percentage \\
\hline Strongly agree & 13 & 4.1 \\
\hline Agree & 7 & 2.2 \\
\hline Disagree & 257 & 80.5 \\
\hline Strongly disagree & 42 & 13.1 \\
\hline Total & 319 & 100 \\
\hline
\end{tabular}

Source: Own survey, 2020

As demonstrated from the above table, the majority of respondent which accounts $257(80.5 \%)$ of were disagreed toward 
the killer scene of covid-19 disease. Similarly, 42(13.1\%) respondents were disagree about covid-19 has been the killer of peoples who will be victim by it. On the contrary of response of majority response, 4.1 percent of respondents were strongly agreed on the killer of covid-19. Eventually, the remains 2.2 percent of respondents agreed and believed that covid-19 is the killer disease which has pervasive across the countries. In a similitude avenue, majority of informants inform that the community of this Woreda was not apparently reckoned the severity and the killer of newly emerged pandemic. According to one informant:

"Peoples consider and assume that without the will of God, covid-19 could not kill them, but they perceived that if God orders them for death, they cannot emancipate from it by taking care. As per this, peoples perceived that covid-19 is the acrimony of God that no one swear from it by wearing mask and keeping physical distance by sparing contacting to each other. Instead peoples opted to go to church for pray and invoke god to heal from his acrimony by cast aside of wearing mask. "

In general, according to the response of the respondent, peoples of Sekela Woreda were not vividly comprehend the killer of covid-19 that finish of human being instead saw it as acrimony of God which has not be protect it by taking care from contacting to each other. Hence, they only opted to praying for God so as to spay and shootout the newly emerged pandemic covid-19.

\subsection{The social impacts of pandemic covid-19 on the community}

The second objective of this investigation has been the social impacts of pandemic covid-19. Therefore, as per this health related problems, on education, social security of the community has been glanced thoroughly during data collection and presented below here:-

\subsubsection{Health related impacts of covid-19}

\section{Table-4 the habits of respondents visiting hospital after} emerging of covid-19

\begin{tabular}{|l|l|l|}
\hline $\begin{array}{l}\text { Do you immediately go to } \\
\text { clink or hospital while you } \\
\text { feel sickness? }\end{array}$ & Frequency & Percentage \\
\hline Yes & 125 & 39.2 \\
\hline No & 194 & 60.8 \\
\hline Total & 100 & 100 \\
\hline
\end{tabular}

Source: own survey; 2020

As depicted from the above table, most of the respondents which account $60.8 \%$ were not intended to go to hospital and from other health service provider center. However, $39.2 \%$ of respondents visit hospitals, and takes health experts advices as well as the needful services which has provided in the hospital. Along this, most of respondents narrates the reason that hinder them to go to hospital during feeling of sickness is that because after came of covid-19 many people's were put under quarantine. Similarly, key informants inform that after emergency of covid-19 in Ethiopia many peoples who have demonstrate symptoms of sickness were not willing to go to hospital and gain assistant from health experts. According to informants, the rationale for restrains of peoples to go to hospital is that, peoples consider and perceived that government will kill them through giving poison if they have getting and victims of covid-19 during treatment.

According to the reports of one informant about the health related problems of covid-19 bring on the peoples as follows:

"Peoples were not agree to consult health experts while feeling of sickness instead opted to hide themselves from else peoples by frustrating and suspecting that if their neighbors aware his/her sickness, they will inform for health experts and insert him/her in to quarantine."

Therefore, one can understand that currently peoples were not utilize health services while feeling of sickness rather opt to use other traditional healing mechanism in order to far apart from contacting with health experts.

\section{Table-5 the current provision of health services}

\begin{tabular}{|l|l|l|}
\hline $\begin{array}{l}\text { The current provision of } \\
\text { health services for the } \\
\text { peoples is good enough } \\
\text { after emerging of covid- } \\
19 ?\end{array}$ & Frequency & Percentage \\
\hline Strongly agree & 45 & \\
\hline Agree & 154 & 14.1 \\
\hline Disagree & 115 & 48.3 \\
\hline Strongly disagree & 5 & 36 \\
\hline Total & 319 & 1.5 \\
\hline
\end{tabular}

Source: own survey, 2020

As shown from the table above, the majority of respondents which accounts 48.3 percents were agreed and satisfied with the provisions of health services which are accessed and found in the health care centers. However, the second majority respondents, 36 percent were dissatisfied by the current health services provision. In accrue with that, the least number of respondents which accounts 1.5 percent were strongly dissatisfied by the current provisions of health services after the emerged of pandemic covid19 in Ethiopia. Similarly, informants notified that the accessibility of safe and sufficient bed room for the patient is so scant and limited yet. Hence, as per the report obtained from informants (health experts), despite federal government allocate budget to protect covid-19 and distribute for each Regions, the provisions of health service center and health experts are highly limited.

Therefore, the current provision of health service for the people has been limited and reached for them as per their desire unfortunately. Notwithstanding government give special and due attention for protecting the spread of newly emerged pandemic covid-19 in over wide, the means of tackling covid-19 is so scant and not be cogent in fact.

\subsubsection{The impacts of covid-19 on education}

The newly emerged pandemic covid-19 has huge impacts to run the normal class all over the country. As a result, students faced different problems after emerged of this outrageous disease in Ethiopia as presented below here:- 
Table-6 impacts of covid-19 on students

\begin{tabular}{|l|l|l|}
\hline $\begin{array}{l}\text { Does covid-19 brought } \\
\text { problems on students? }\end{array}$ & Frequency & Percentage \\
\hline Yes & 319 & 100 \\
\hline No & - & - \\
\hline Total & 100 & 100 \\
\hline
\end{tabular}

Source: own survey, 2020

As presented from the table above, all respondents which accounts $100 \%$ of them responded that, the emergency of pandemic covid-19 bring great problems on students to attend their schooling in due. Correspondingly, key informants, especially Woreda education experts inform that covid-19 bring huge negative impacts on students to follow their education as per scheduled time. As a result, many high school and primary school students were vulnerable for early marriage unfortunately. As reported by key informants, parents were giving up on the opening of school and resuming of teaching and learning process as of normal. Inconsequent, students were opted to marry with and without their consent instead of attend their schooling after reopening of school. According to the informant some students were impelled to married by the impulse of their parents unfortunately. Besides, the emergency of pandemic covid-19 has brought a psychological devastation on grade twelve (12) students (entrance examinees) those who are ready to take entrance exam during 2020. Hence, those students (entrance examinees) were not feel confidence for the launching of schooling in the next and have not trust on government, because ministry of education extends and changes the due date of the delivery of entrance exam more than three times, and does not takes place hither to.

\subsubsection{The impacts of covid-19 on the social security of the community}

The newly emerged covid-19 has brought great social malaise in the community. Since peoples were encounter varied social vices in fact as demonstrated in the chart below:-

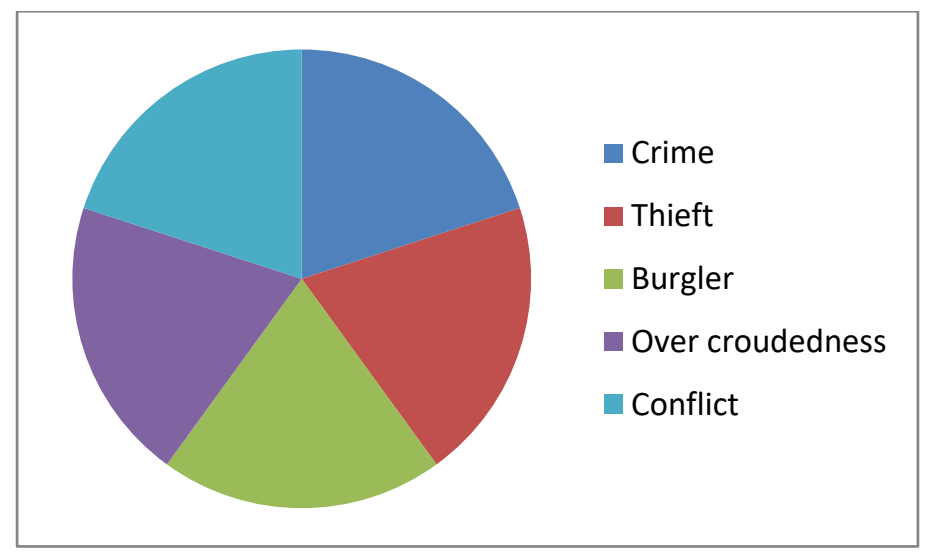

As depicted in the above pie chart, there are different social vices that happened in the area which had been emanated from the emergency of covid-19 in the Ethiopia. Hence, as stated by informants, daily laborers were not able to attain their basic needs instead opted to engage in theft to satisfy hunger feeling, because the availability of job is come to scarce. Many daily laborers were came from other areas to their home area by frustrating the covid19 , and those workers cannot attain birr's that will cover their needs except through wheedle and besought to their families. As a result when they are being empty pocket, they opted to stolen the property of else who and engaged in the practices of burglar their family and others house to stolen purpose unfortunately. As informed by police officers, youth were advents to conflicting to each other. Since, universities and colleges release their students to their home area and getting contact with other daily laborers; these eliciting many youth were form squads and engaged in conflict around game zone and elsewhere.

\subsection{Economic impacts of newly emerged covid-19 on the society}

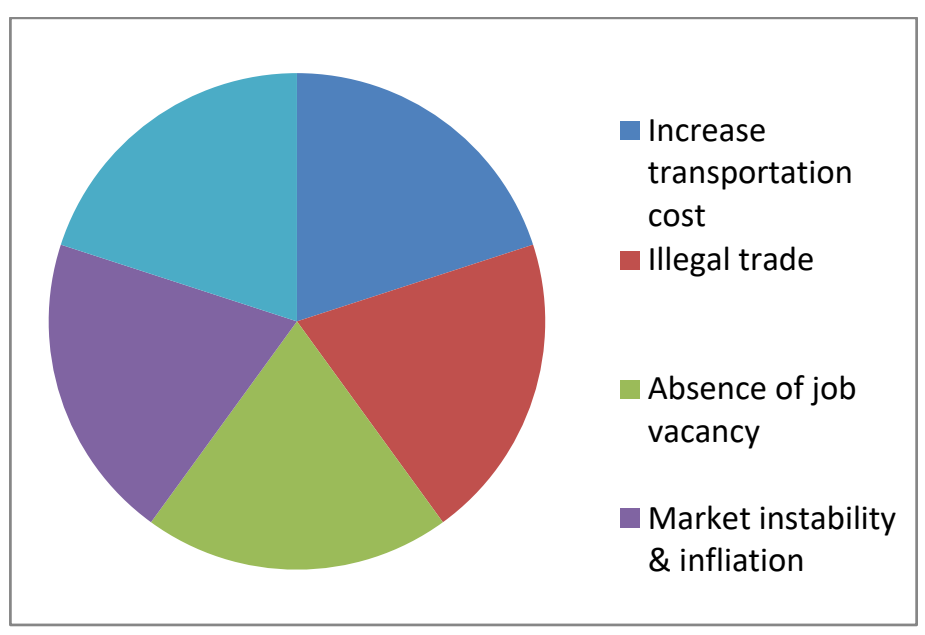

As presented in the above pie chart, covid-19 has brought tremendous and devastating impacts on the economic instability of the country. Notwithstanding it came to hold its normal service provision to day, in earlier transportation system, like the price of transport has been increased by half per person and the holding capacity of one vehicle has been reduced by half so as to protect the pervasive of newly emerged covid-19 in the country. Besides, this outrageous disease has suffered daily laborers whose daily consumption is relying on daily work. Actually, those workers have not reserve birr's that served for purchasing their needs. Accordingly, absence of job for those daily laborer impel them to engage in legally inacceptable activities that would them to be accountable as per their deed, like theft hanging and snach the property of other peoples. Not only the aforementioned problems have been manifested in the area, but absence of job vacancy brought graduates to be unemployed and in turn affect the motivation of their young students unfortunately. In accrue with that, peoples were opted to engage in illegal trade that elicit them in to prison while they catches by police man. Therefore, the implication of newly emerged pandemic covid-19 susceptible peoples for myriads of problems that make them to put in void of life. 


\section{CONCLUSION AND RECOMMENDATIONS}

In this section in light of the analysis of the information gathered from the respondents and informants, the following results and conclusion were drowned.

\section{Conclusion}

While researcher endeavor to recapitulate the investigation; the perception of community toward the severity of newly emerged pandemic covid-19 has been low so. Due to this scene, the probability of peoples to be victimize by covid-19 is resembles to high. Despite, government strives to provide health related services for the people; it seems scant and not takes it as of cogent hither to. Covid-19 has brought tremendous negative impacts on the social and economic scenes of the society. These are conflict, theft, illegal trade, over crowdedness of the area and other social malaises are characterized and demonstrated in the area. Besides, the stability market came to pendulum by the cause of emerged new pandemic. Not only market instability, but absence of the availability of job for daily labors elicits other problem for laborers in particular and on the community at a large. Thereof, government stakeholders' have a great responsibility to heal peoples from this outrageous pandemic disease by creating awareness and take various measurement.

\section{Recommendations}

While the researcher going to the recommendations based upon the major finding of the study, researcher brought some recommendations that expected to reduce and ameliorate the problem as well as to take remedies on it. Among the forwarded recommendation which has believes to be the measurements of the severity of the issues are presented as follows:-

$\checkmark$ From the very inception, government stakeholders, particularly health experts should create awareness about the severity of newly emerged disease for the society and convince them to gain first aid while they feel sickness symptom. $\checkmark$ Peoples should attentively listen and apply the proclamations of government that designed to hinder the pervasiveness of covid-19.

$\checkmark$ Government stakeholders, particularly small and micro enterprise experts should keep the stability of market price and its transaction system.

$\checkmark \quad$ Woreda police officers should deliver ethical education for youths and make them to be patient.

Students parent should be restrain from taking hideous measurement on their kids and impel them to marry by dropping their schooling.

\section{REFERENCES}

[1] Abawi, K. (2013). Data Collection Instruments (Questionnaire \& Interview) . Geneva: Geneva Foundation for Medical Education and Research.

[2] Abawi, K. (2014). Data Collection Instruments (Questionnaire \& Interview). Geneva: Geneva Foundation for Medical Education and Research.

[3] Ayhan, H. (2011). Non-probability Sampling Survey Methods. Springer, Berlin, Heidelberg, P,1-2.

[4] Bank, W. (2020). East Asia and Pacific in the Time of Covid-19. World Bank East Asia and Pacific Economic update, p. 234. Retrived from https://doi.org/10.1596/978-1-4648-1565-2. https://openknowledge. worldbank.org/handle/10986/33477.

[5] Martin, A. \&. (2020). Socioeconomic impacts of covid-19 on household consumption and poverty. Springer nature Switherland , p, 472.

[6] Sozi, C. (2020). socioeconomic impacts of covid-19 in ethiopia. United Nation , P. 1-2.

[7] WHO. (2020). corona virus. World health organization.

[8] WHO. (2020). Water, sanitation, hygiene, and waste management for the COVID-19 virus in Ethiopia. World Health Organisation, P,3.

[9] World Bank. (2020). Draft Analysis - COVID-19: Potential Poverty and Social Impacts in Ethiopia and Policy Responses. World bank, P,4.

\section{AUTHORS}

First Author - Abie Assres Fenta (Lecturer in Department of Sociology, At Debre Markos University, Ethiopia), Email: abieasres87@gmail.com 